\section{Localized and Recurrent Angioedema of the Lips Successfully Treated with a Radiofrequency Device}

Keywords: Angioedema; Dermal coagulation; Radiofrequency device

Angioedema is characterized by swelling of the deeper layer of the skin and/or the submucosa. It is usually localized, sudden, and transient, lasting from several hours to a few days and is often recurrent. The swellings develop from extravasation of plasma in the affected areas because of a transient increase in endothelial permeability caused by vasoactive substances produced locally [1]. Histopathologically, it presents as localized dermal edema with separation of collagen fibers and dilated venules with endothelial swelling, along with the presence of variable number of lymphocytes, eosinophils and neutrophils [2]. In this study, we report the effect of a radiofrequency $(\mathrm{RF})$ device on localized and recurrent angioedema on the lips.

A 34-year-old woman visited our clinic for recurrent facial and lip

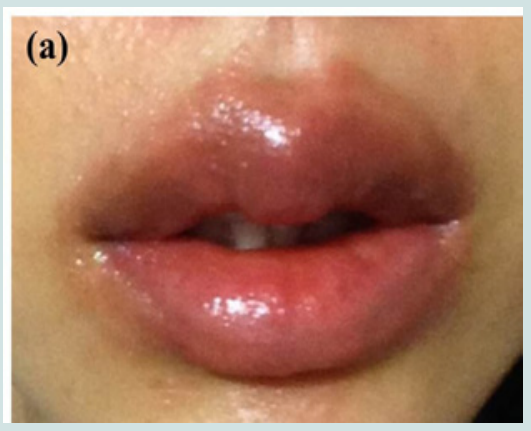

Figure 1: (A) She exhibited mild erythematous swollen lips before development of the angioedema attack.

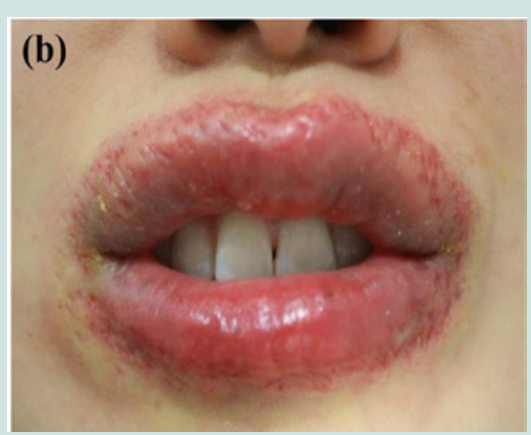

(B) After procedure.

\section{Journal of}

\section{Clinical \& Investigative} Dermatology

\author{
Hyun Jung Kwon, Ga Ram Ahn, Joon Seok and Beom \\ Joon Kim* \\ Department of Dermatology, Chung-Ang University College of Medicine, \\ Seoul, Korea \\ *Address for Correspondence \\ Beom Joon Kim, Department of Dermatology, Chung-Ang University College \\ of Medicine, Chung-Ang University Hospital 224-1 Heukseok-dong, Dongjak- \\ gu, Seoul 156-755, Korea, Tel: +82.2-6299-1525; Fax: +82.2-823-1049; E-mail: \\ beomjoon@unitel.co.kr \\ Submission: 26 February, 2017 \\ Accepted: 13 March, 2017 \\ Published: 18 March, 2017 \\ Copyright: @ $2017 \mathrm{Kwon} \mathrm{HJ}$, et al. This is an open access article distributed \\ under the Creative Commons Attribution License, which permits unrestricted \\ use, distribution, and reproduction in any medium, provided the original work \\ is properly cited.
}

swelling, once or twice a month lasting over 1 year (Figure 1A). The swelling was non-tender, non-pitting and not warm. Other cutaneous lesions including hives were not accompanied. She complained burning sensation on her lips whenever it was repeated. The patient had no special family history and no known exposure of drugs, foods, or chemical agent that would cause this swelling. Her vital signs were stable and physical examination was unremarkable. Laboratory findings showed normal blood chemistry, eosinophil count, total IgE level and negative for multiple allergen simultaneous tests. She was negative for antinuclear antibodies and rheumatoid factors, and her serum complement level was also normal. Under the diagnosis of idiopathic angioedema, she was treated with systemic corticosteroid (methylprednisolone $20 \mathrm{mg} / \mathrm{d}$ for 1-2 days) and second generation antihistamine (H1-receptor antagonist), which reduced her swelling within a few days. Though she had quick and favorable response to corticosteroid in acute phases, the swelling was appeared on lips again after 1 week of stopping oral medication. We started with an omalizumab with an initial monthly dose of $300 \mathrm{mg}$ with an avoidance of long-term use of corticosteroid. Unfortunately, she didn't show the remission for a long period despite immediate response on omalizumab administration. At last, we experimentally tried to use AGNES $^{\circ}$ on recurrent lip swelling, recently developed RF device (Gowoonsesang Cosmetics Co., Seoul, Korea). Before the procedure, topical anesthetic cream (EMLAs ; AstraZeneca, Wilmington, DE, USA) was applied around her lips for $30 \mathrm{~min}$. We applied a current at the frequency of $120 \mathrm{~m} \mathrm{sec}$, the intensity of power level 2, and 1 $\mathrm{MHz} \mathrm{RF}$ apparatus within sulated C-type needles. The distal part of the needle that was uncovered by insulation directly delivered RF waves at the dermal level, while sparing the epidermis. The patient was treated with a single session of the insulated microneedle RF along the vermilion border on her lips (Figure 1B). No post treatment analgesic medications were required other than the application of cold gauze to treated site for $10 \mathrm{~min}$. After the procedure, a layer of petrolatum jelly was applied to the treated area (Figure 1C). Lip swelling was significantly improved after 3 weeks of single treatment from RF device and improved condition persisted for over 3 months 


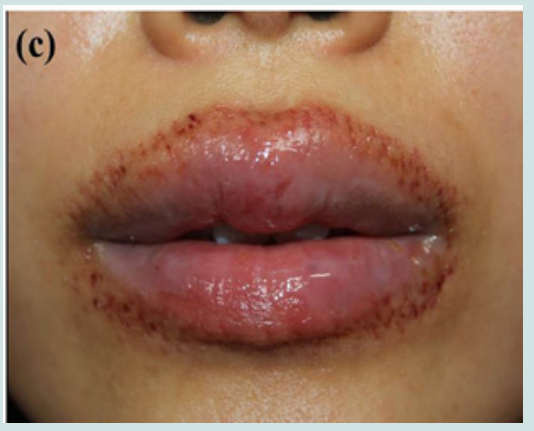

(C) 24 hours after procedure

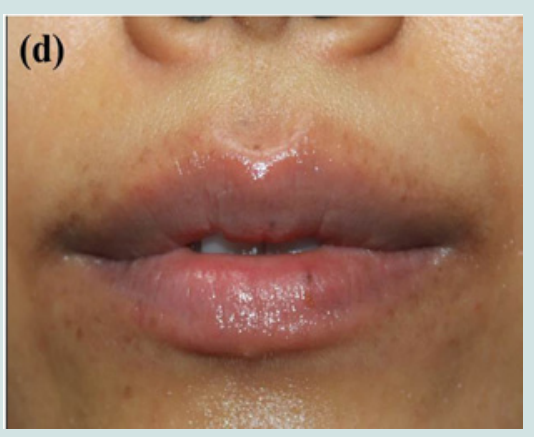

(D) The swelling of the lips was significantly improved after 3 weeks of single session of treatment from RF device.

\section{(Figure 1D)}

Idiopathic acquired angioedema is assumed to be a subgroup of patients with chronic urticaria. No allergic etiology can be found, their health is otherwise normal, complement studies ( $\mathrm{C} 4$ $\mathrm{C} 1 \mathrm{INH}$ by protein and function) are normal, and there is no familial predisposition. The pathogenesis of this disorder is not known. Recent attempts to treat angioedema have stepwise divided non sedating antihistamines, leukotriene synthesis inhibitor, tranexamic acid and omalizumab [3]. Omalizumab is a recombinant humanized monoclonal anti-IgE antibody. It is the first monoclonal antibody approved for patients with chronic spontaneous urticaria nonresponsive to antihistamines and for severe allergic asthma. In several recent studies, they reported rapid response of omalizumab in recurrent idiopathic angioedema [4].

To our knowledge, this is the first report of therapeutic efficacy of radiofrequency in idiopathic angioedema. Theoretically, microneedle RF device delivers uniform heat at controlled depth to the dermal layers, resulting in immediate collagen shrinkage and subsequent neocollagenesis. Reticular dermal volume, cellularity, hyaluronic acid and elastincontent were also increased [5]. In vitro study also shows it created conical diamond shaped tissue coagulation in the dermis. Periadnexal collagen and interstitial collagen have been shown to be coagulated with RF treatment, whereas blood vessels, sweat glands, sebaceous glands, hair follicles, and fat tissue are well preserved [6]. This mechanism ultimately prevents loosening of dermal tissue by increasing perivascular cellularity. Although RF device does not modify vascular response to vasoactive substance, increasing in density and thickness of collagen bundle might help to lower the possibility of widening intervascular space in dermis as shown in skin tightening. We expect this dermal ablation effect to prevent recurrence of angioedema. Through this trial, we propose the application of this novel monopolar RF microneedle device in the treatment of localized angioedema refractory to other conventional treatments.

\section{References}

1. Frigas E, Park M (2006) Idiopathic recurrent angioedema. Immunol Allergy Clin North Am 26: 739-751.

2. Stewart GE 2nd (2002) Histopathology of chronic urticaria. Clin Rev Allergy Immunol 23: 195-200.

3. Cicardi M, Bergamaschini L, Zingale LC, Gioffré D, Agostoni A (1999) Idiopathic nonhistaminergic angioedema. Am J Med 106: 650-654.

4. Sands MF, Blume JW, Schwartz SA (2007) Successful treatment of 3 patients with recurrent idiopathic angioedema with omalizumab. J Allergy Clin Immunol 120: 979-981.

5. el-Domyati M, el-Ammawi TS, Medhat W, Moawad O, Brennan D, et al. (2011) Radiofrequency facial rejuvenation: evidence-based effect. J Am Acad Dermatol 64: 524-535.

6. Hantash BM, Renton B, Berkowitz RL, Stridde BC, Newman J (2009) Pilot clinical study of a novel minimally invasive bipolar microneedle radiofrequency device. Lasers Surg Med 41: 87-95 